\title{
GAYA KEPEMIMPINAN DAN LINGKUNGAN KERJA BERPENGARUH TERHADAP KINERJA KARYAWAN MELALUI MOTIVASI KERJA PT. MINA JAYA LESTARI SURABAYA
}

\author{
Al Anva Dewi Layungsari ${ }^{1}$, Untung Lasiyono ${ }^{2}$, Tri Ari Prabowo ${ }^{3}$ \\ Universitas PGRI Adi Buana Surabaya ${ }^{1,2,3}$ \\ anvadewi13@gmail.com
}

\begin{abstract}
ABSTRAK
Dijelaskan analisa pengaruh gaya kepemimpinan dan lingkungan kerja terhadap kinerja karyawan melalui motivasi kerja pada PT.Mina Jaya Lestari. Sampel yang digunakan adalah 113 orang. Teknik memakai non probability dengan teknik Random sampling. Analisis data menggunakan path analysis. Diperoleh hasil Gaya Kepemimpinan dan lingkungan kerja berpengaruh positif dan signifikan terhadap Motivasi Kerja Karyawan pada PT. Mina Jaya Lestari Surabaya, Gaya Kepemimpinan, lingkungan kerja dan motivasi kerja berpengaruh positif dan signifikan terhadap kinerja karyawan pada PT. Mina Jaya Lestari Surabaya. Hasil pengujian hipotesis menggunakan ujit dan uji-sobel. Dimana hasil tersebut menunjukkan terdapat pengaruh signifikan, hipotesis bisa diterima dan terbukti kebenarannya.
\end{abstract}

Kata kunci: Gaya Kepemimpinan, Lingkungan Kerja, Motivasi Kerja, Kinerja karayawan

\begin{abstract}
The Explained research to analized the influence of leadership style and work environment on employee performance through work motivation at PT.Mina Jaya Lestari. The sample used was 113 people. The technique uses non probability with the technique of random sampling. used several tests path analysis. The test results obtained by the Leadership Styles and work environments have a positive and significant effect on Employee Motivation at PT. Mina Jaya Lestari Surabaya, Leaderships Style, work enviroment and work motivation have a positive and significant effect on employee performance at PT. Mina Jaya Lestari Surabaya. Results of testing the hypothesis using the test and sobel-test. Where these results indicate there is a significant influence, so the hypothesis can be accepted and proven true.
\end{abstract}

Keywords: Leadership Style, Work Environment, Work Motivation, Employee Performance 


\section{Latar Belakang}

Gaya kepemimpinan yang menunjukkan secara langsung maupun tidak langsung, tentang keyakinan seorang pimpinan terhadap kemampuan bawahannya. Hal yang harus diperhatikan selanjutnya adalah lingkungan kerja. Lingkungan kerja yang kurang nyaman, dapat membuat karyawan satu persatu menarik diri dari perusahaan dengan alasan tidak betah dengan lingkungan yang ada di perusahaan tersebut, sebab kondisi perusahaan yang panas, gudang yang kotor dan bau serta polusi udara yang mengganggu. Seiring berkembangnya teknologi dan pengetahuan, Kinerja karyawan yang tinggi dibutuhkan perusahaan. jika karyawan mempunyai kinerja yang tinggi. Sebagai seseorang pemimpin memberikan motivasi kepada para bawahannya itu sangatlah penting karena motivasi sangat dibutuhkan bawahan untuk meningkatkan semangat mereka.

PT. Mina Jaya Lestari Surabaya didirikan oleh Bapak Sugeng Tjahjono pada tahun 2004. Perusahaan ini berlokasi di Pergudangan Margomulyo Permai J-12, Surabaya. Memiliki 6 staff admin gudang, 3 staff admin back office, 2 staff IT, 84 karyawan produksi dan 5 karyawan pada divisi teknik. Perusahaan ini merupakan salah satu bisnis keluarga dimana yang menjadi pengelolanya merupakan anak-anak dari pemilik perusahaan. PT. Mina Jaya Lestari Surabaya merupakan perusahaan dagang yang memproduksi olahan ikan dalam bentuk beku untuk tujuan lokal dan ekspor. Perusahaan ini mempunyai banyak anak cabang yang terletak di Bitung, Kendari, Bogor, Tangerang, Prigi, Palu, dan Muncar. Induk perusahaan ada di Surabaya.

PT. Mina Jaya Lestari Surabaya banyak melakukan perubahan, baik dari segi SDM, pemasaran, operasional, dan keuangan, serta penyediaan alat-alat (mesin) yang berkualitas. Lingkungan kerja yang nyaman bagi karyawan dapat menjadi daya tarik sebuah perusahaan untuk mengikat karyawan agar dapat bekerja dalam perusahaan tersebut. Sumber daya manusia pada PT. Mina Jaya Lestari perlu dikelola secara profesional agar terwujud keseimbangan antara apa yang dibutuhkan karyawan dengan apa yang menjadi tuntutan dan seberapa mampu organisasi untuk bertahan secara stabil.

\section{Rumusan Masalah}

1. Apakah Gaya Kepemimpinan berpengaruh terhadap Motivasi Kerja Karyawan?

2. Apakah Lingkungan Kerja Berpengaruh terlhadap Motivasi Kerja karyawan?

3. Apakah Gaaya Kepemimpinan berpeengaruh terhadap Kineerja Karyawan?

4. Apaakah Lingkungan Kerja berpengaruh terhadap Kinerja Karyawan?

5. Apakah Motivasi berpengaruh terhadap Kinerja Karyawan?

6. Apakah Gaaya Kepemimpinan melalui Motivasi Kerja beerpengaruh teerhadap Kinerja Karyawan?.

7. Apakah Lingkungan Kerja melalui Motivasi Kerja berpengaruh ke Kinerja Karyawan?

\section{Tujuan penelitian}

1. Supaya bisa mengetahui pengaruh Gaya Kepemiimpinan terhadap Motivasi Karyawan.

2. Supaya bisa mengetahuii pengaruh Lingkungan Kerja terhadap Motivasi Kerja Karyawan.

3. Supaya bisa mengetahui pengaruh Gaya Kepemimpinan terhadap Kinerja.

4. Supaya bisa mengetahui pengaruh Lingkungan Kerja terhadap Kinerja Karyawan.

5. Supaya bisa mengetahui pengaruh Motivasi Kerja terhadap Kinerja Karyawan.

6. Supaya bisa mengetahui pengaruh Gaya Kepemimpinan melalui Motivasi Kerja pada Kinerja karyawan.

7. Supaya bisa mengetahui bagaimana pengaaruh Lingkungan Kerja melalu Motivasi Kerja terhadap Kinerja Karyawan. 


\section{TINJAUAN PUSTAKA}

Kinerja ialah pencapaian karyawan dalam menjalankan pekerjaan yang dibebabkan oleh perusahaan. indikator kinerja karyawan diukur dengan 6 dimensi yaitu:

1. Kecepatan kerja

2. Kedisiplinan

3. Pengetahuan

4. Kualitas diri.

5. Inisiatif.

6. Kualitas kerja

Gaya kepemimpinan adalah sebuah cara yang dipakai piimpinan suatu perusahaan dalam mempengaruhi bawahannya dalam meningkatkan kinerja agar tujuan perusahaan dapat tercapai. indikator nya adalah:

1. Kemampuan dalam mengambil keputusan.

2. Memberi motivasi

3. Dapat berkomunikasi

4. Dapat mengendalikan bawahannya.

5. Tangung jawab

6. Mampu mengendalikan emosi

Sebuah koindisi yang ada disekitar perusahaan yang dapat menunjang karyawan dalam melakukan pekerjaannya. indikator lingkungan kerja:

1. Pertukaran udara.

2. Kebersihan

3. Kebisingan

4. Keamanan

5. Pencahayaan

Motivasi adalah bentuk faktor yang memberikan dorongan pada seorang untuk melakukan kegiatan tertentu.

indikator untuk mengukur motivasi kerja adalah:

1. Promosi guna pencapian tujuan.

2. Dorongan untuk bekerja lebih baik

3. Inisiatif dan kreativitas.

4. Bertanggungjawab 


\section{Kerangka Konseptual}

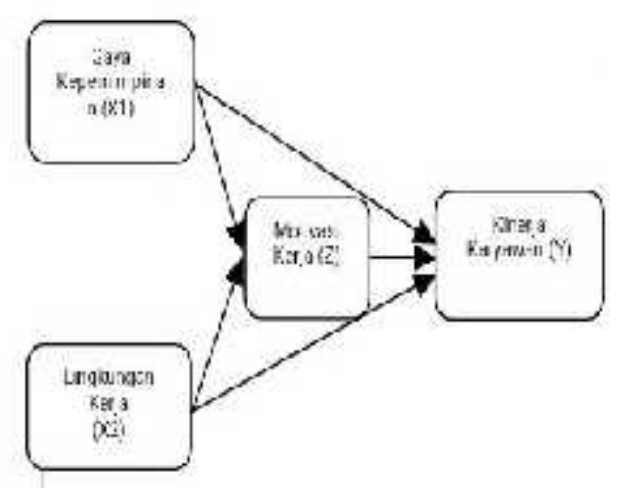

HASIL \& PEMBAHASAN

Tabel 1 Hasil Uji Validitas

\begin{tabular}{|c|c|c|c|c|}
\hline \multirow{2}{*}{ Item Pernyataan } & \multirow{2}{*}{$\begin{array}{c}\text { Hasil Korelasi } \\
\left(r_{\text {hitung }}\right) \\
\end{array}$} & \multirow{2}{*}{$\frac{\text { Nilai Kritis }}{\left(\mathrm{r}_{\text {tabel }}\right)}$} & \multirow{2}{*}{$\begin{array}{l}\text { Nilai } \\
\text { Sig. }\end{array}$} & \multirow{2}{*}{ Keterangan } \\
\hline & & & & \\
\hline \multicolumn{5}{|c|}{ Gaya Kepemimpinan $\left(X_{1}\right)$} \\
\hline$X_{1.1}$ & $.966^{* *}$ & 0,2096 & 0,000 & Valid \\
\hline$X_{1} .2$ & $.942^{* *}$ & 0,2096 & 0,000 & Valid \\
\hline$X_{1} .3$ & $.938^{* *}$ & 0,2096 & 0,000 & Valid \\
\hline $\mathrm{X}_{1.4}$ & $.938^{* *}$ & 0,2096 & 0,000 & Valid \\
\hline$X_{1.5}$ & $.946^{* *}$ & 0,2096 & 0,000 & Valid \\
\hline$X_{1} .6$ & $.956^{* *}$ & 0,2096 & 0,000 & Valid \\
\hline \multicolumn{5}{|c|}{ Lingkungan Kerja $\left(\mathrm{X}_{2}\right)$} \\
\hline $\mathrm{X}_{2.7}$ & $.958^{* *}$ & 0,2096 & 0,000 & Valid \\
\hline$X_{2.8}$ & $.954^{* *}$ & 0,2096 & 0,000 & Valid \\
\hline$X_{2.9}$ & $.935^{* *}$ & 0,2096 & 0,000 & Valid \\
\hline $\mathrm{X}_{2.10}$ & $.941^{* *}$ & 0,2096 & 0,000 & Valid \\
\hline$X_{2.11}$ & $.932^{* *}$ & 0,2096 & 0,000 & Valid \\
\hline \multicolumn{5}{|c|}{ Motivasi Kerja (Z) } \\
\hline Z.12 & $.944^{* *}$ & 0,2096 & 0,000 & Valid \\
\hline Z.13 & $.921^{* *}$ & 0,2096 & 0,000 & Valid \\
\hline Z.14 & $.921^{* *}$ & 0,2096 & 0,000 & Valid \\
\hline Z.15 & $.951^{* *}$ & 0,2096 & 0,000 & Valid \\
\hline \multicolumn{5}{|c|}{ Kinerja $(\mathrm{Y})$} \\
\hline Y.16 & $.943^{* *}$ & 0,2096 & 0,000 & Valid \\
\hline Y.17 & $.943^{* *}$ & 0,2096 & 0,000 & Valid \\
\hline Y.18 & $.918^{* *}$ & 0,2096 & 0,000 & Valid \\
\hline Y.19 & $.938^{* *}$ & 0,2096 & 0,000 & Valid \\
\hline$Y .20$ & $.914^{* *}$ & 0,2096 & 0,000 & Valid \\
\hline Y.21 & $.932^{* *}$ & 0,2096 & 0,000 & Valid \\
\hline
\end{tabular}


Sumber :Lampiran Output SPSS Pengujian uji validitas.

Adapun hasil dari menguji validitas pada semua item dari setiap pernyataan mempunyai signifikansi $(\leq 0,05)$, sehingga keseluruhan item di anggap valid.

Tabel 2 Uji Reliabilitas

\begin{tabular}{lccc}
\hline \multicolumn{1}{c}{ Variabel } & $\begin{array}{c}\text { Nilai alpha } \\
\text { cronbach }\end{array}$ & $\begin{array}{c}\text { Nilai } \\
\text { Kritis }\end{array}$ & Keterangan \\
\hline $\begin{array}{l}\text { Gaya } \\
(\mathrm{X} 1)\end{array}$ & 0,977 & 0,6 & Reliabel \\
\hline Lingkungan Kerja (X2) & 0,969 & 0,6 & Reliabel \\
\hline Motivasi Kerja (Z) & 0,951 & 0,6 & Reliabel \\
\hline Kinerja (Y) & 0,970 & 0,6 & Reliabel \\
\hline
\end{tabular}

Sumber :Lampiran Output SPSS Pengujian Instrumen, data diolah

Dijelaskan diperoleh hasil nilai reliabel, sehingga kuesioner yang dibuat sebagai bahan acuan untuk penelitian dapat diterima responden dengan baik dan layak untuk dilanjutkan sebagai instrument penelitian.

Tabel 3 Uji Normalitas

\begin{tabular}{llr}
\multicolumn{2}{c}{ One-Sample Kolmogorov-Smirnov Test } \\
\hline & & \multicolumn{1}{c}{$\begin{array}{c}\text { Unstandardized } \\
\text { Residual }\end{array}$} \\
\hline $\mathrm{N}$ & Mean & 88 \\
\cline { 2 - 3 } $\begin{array}{l}\text { Normal } \\
\text { Parameters }\end{array}$ & Std. Deviation & $0.00 \mathrm{E}+00$ \\
\hline \multirow{2}{*}{$\begin{array}{l}\text { Most Extreme } \\
\text { Differences }\end{array}$} & Absolute & 5.16705277 \\
\cline { 2 - 3 } & Positive & 0.102 \\
\cline { 2 - 3 } & Negative & 0.047 \\
\hline Kolmogorov-Smirnov Z & -0.102 \\
\hline Asymp. Sig. (2-tailed) & 0.953 \\
\hline
\end{tabular}

Sumber :Lampiran Output SPSS Pengujian Normalitas Data, data diolah

Dijelaskan uji normalitas diperoleh hasil sig 0,451 >0,05. Jadi model regresi berdistribusi secara normal, sehingga peneliti dapat melakukan uji selanjutnya. 
Tabel 4 Uji Multikolinieritas

Coefficients ${ }^{\mathrm{a}}$

\begin{tabular}{rlrr}
\hline \multirow{2}{*}{ Model } & \multicolumn{2}{c}{ Collinearity Statistics } \\
\cline { 3 - 4 } & Tolerance & \multicolumn{1}{c}{ VIF } \\
\hline \multirow{2}{*}{1} & Gaya Kepemimpinan $(\mathrm{X} 1)$ & 0.767 & 1.304 \\
\cline { 2 - 4 } & Lingkungan Kerja $(\mathrm{X} 2)$ & 0.672 & 1.489 \\
\cline { 2 - 4 } & Motivasi Kerja $(\mathrm{Z})$ & 0.708 & 1.412 \\
\hline
\end{tabular}

a. Dependent Variable: Kinerja (Y)

Sumber :Lampiran Output SPSS Pengujian Multikolinieritas

Dijelaskan uji multikolinieritas menunjukkan bahwa model dari regresi tersebut tak ada masalah atau bebas dari uji multikolinieritas.

\section{Tabel 5 Hasil Uji Autokorelasi} Model Summaryb

\begin{tabular}{lcc}
\hline Model & \multicolumn{3}{c}{ Durbin-Watson } \\
\hline 1 & $1.679^{\mathrm{a}}$
\end{tabular}

Sumber : Lampiran Output SPSS Pengujian Multikolonierita

Dijelaskan autokorelasi merujuk pada nilai dari DW yakni sebesar 1,679. Nilai DW berada diantara nilai $1,55<1,679<2,46$.

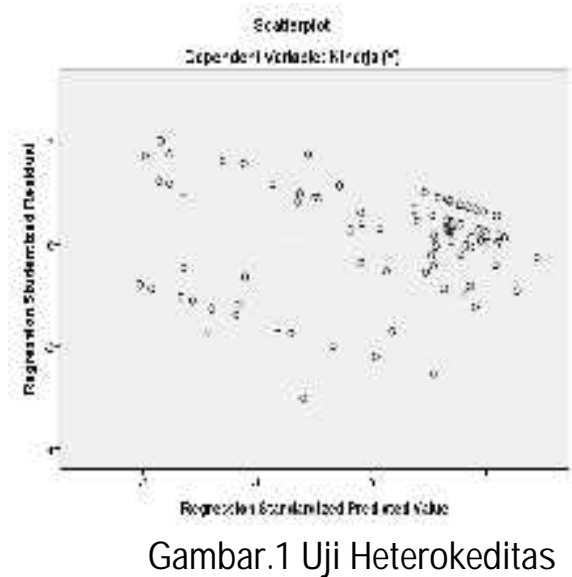

Dijelaskan Scatterplot diatas terlihat jelas titik - titik menyebar secara acak, tanpa memberi bentuk sebuah pola tertentu dengan jelas, serta tersebar baik di atas ataupun dibawah angka 0 disumbu $Y$. 


\section{Analisis Jalur}

Uji Sub Struktural 1

Tabel 6 Hasil Pengujian Sub Struktural 1

\begin{tabular}{|c|c|c|c|}
\hline \multicolumn{4}{|c|}{ Coefficients $^{a}$} \\
\hline \multirow{2}{*}{ Model } & & \multicolumn{2}{|c|}{$\begin{array}{l}\text { Unstandardized } \\
\text { Coefficients }\end{array}$} \\
\hline & & $\mathrm{B}$ & $\begin{array}{l}\text { Std. } \\
\text { Error }\end{array}$ \\
\hline \multirow{3}{*}{1} & (Constant) & 7.218 & 1.45 \\
\hline & Gaya Kepemimpinan (X1) & 0.124 & 0.061 \\
\hline & Lingkungan Kerja (X2) & 0.292 & 0.071 \\
\hline
\end{tabular}

Sumber : Lampiran uji regresi linier

Dijelaskan persamaan regresi berikut ini :

$Z=7,218+0,124 X_{1}++0,292 X_{2}+e$

Penjelasannya sebagai berikut:

1. Dijelaskan nilai konstanta 7,218 . maka nilai darivariabel motivasi sebesar 7,218 .

2. Koefisiens regresi variabel $X_{1}$ adl 0,124 , koefisien regresi dengantanda positif menunjukkan $\left(X_{1}\right)$ berpengaruh searah terhadap variabel $(\mathrm{Z})$

3. Koefisien regresi variabel $\left(X_{2}\right)$ sebesar 0,292 , koefisien regresi menunjukan tanda positif dan menunjukkan variabel $\left(X_{2}\right)$ berpengaruh searah terhadap variabel $(Z)$, yang berarti setiap peningkatan variable $\left(X_{2}\right)$ satu satuan maka akan meningkatkan nilai variabel $(Z)$ sebesar 0,292 satuan.

Pengujian Sub. Struktural 2

Berikut adalah hasil pengujian sub struktural 2.

Tabel 7 Hasil Pengujian Sub Struktural 2 Coefficients $^{\mathrm{a}}$

\begin{tabular}{rlrr}
\hline \multirow{2}{*}{ Model } & & \multicolumn{2}{c}{$\begin{array}{c}\text { Unstandardized } \\
\text { Coefficients }\end{array}$} \\
\cline { 3 - 4 } & & $\mathrm{B}$ & \multicolumn{1}{c}{ Std. Error } \\
\hline & (Constant) & 8.467 & 2.466 \\
\cline { 2 - 4 } 1 & $\begin{array}{l}\text { Gaya Kepemimpinan } \\
\text { (X1) }\end{array}$ & 0.193 & 0.094 \\
\cline { 2 - 4 } & Lingkungan Kerja (X2) & 0.279 & 0.117 \\
\cline { 2 - 4 } & Motivasi Kerja (Z) & 0.357 & 0.162 \\
\hline
\end{tabular}

a. Dependent Variable: Kinerja (Y)

Sumber : Lampiran uji regresi linier 
Berikut adalah persamaan regresi:

$Y=8,467+0,193 X_{1}++0,279 X_{2}+0,357 Z+e$

Dari penjabaran diatas, dijelaskan demikian:

1. Dari persamaan tersebut, nilai konstanta adalah 8,467l, maka nilai variabel kinerja sebesar 8,467.

2. Koefisien regresi dari variable $\left(X_{1}\right)$ sebesar 0,193 , koefisien regresi bertanda positif menunjukkan variabel $\left(X_{1}\right)$ berpengaruh searah terhadap variabel $(Y)$, yaitu setiap peningkatan variabel $\left(X_{1}\right)$ satu satuan dapat meningkatkan nilai variabel $(Y)$ sebesar 0,193 satuan.

3. Koeifisien regresi variabel $\left(X_{2}\right)$ sebesar 0,279 , koefisien regresi bertanda positif menunjukkan variable $\left(X_{2}\right)$ berpengaruh searah terhadap variabel $(Y)$, yang berarti disetiap peningkatan variabel $\left(X_{2}\right)$ dalam satuan akan meningkatkan nilai variabel $(Y)$ sebesar 0,279 satuan.

4. Koefisiens regresi variabel $Z$ 0,357, koefisien regresi bertanda positif menunjukkan variabel(Z) berpengaruh searah terhadap variabel $(Y)$, yang berati setiap peningkatan variabel motivasi kerja $(Z)$ satusatuan akan meningkatkan nilai variabell $(Y)$ sebesar 0,357 satuan.

\section{Pengaruh langsung (dirrect effect)}

\section{Tabel 8 Pengaruh Langsung}

\begin{tabular}{ccc}
\hline Kode & $\begin{array}{c}\text { Pengaruh } \\
\text { Variabel }\end{array}$ & $\begin{array}{c}\text { Pengaruh } \\
\text { langsung }\end{array}$ \\
\hline P1 & $\mathrm{X}_{1}$ Terhadap $Z$ & 0,206 \\
\hline P2 & $\mathrm{X}_{2}$ Terhadap $\mathrm{Z}$ & 0,417 \\
\hline P3 & $\mathrm{X}_{1}$ Terhadap $\mathrm{Y}$ & 0,211 \\
\hline P4 & $\mathrm{X}_{2}$ Terhadap $\mathrm{Y}$ & 0,262 \\
\hline P5 & Z Terhadap $\mathrm{Y}$ & 0,235
\end{tabular}

Sumber: Lampiran Output SPSS, analisis jalur model trimming

Pada tabel 8 diatas tertera pengaruh langsung varibael $\left(X_{2}\right)$ terhadap $(Z)$ sebesar 0,417 adalah yang tebesar.

\section{Pengaruh tidak langsung (indirect effect)}

Penghitungan Pengaruh tak langsung memakai uji Sobel (Sobel test) (Ghozali, 2015;45). Dengan menggunakan rumus sebagai berikut :

$$
\begin{aligned}
\mathrm{X}_{1} \rightarrow \mathrm{Z} \rightarrow \mathrm{Y} & =P 1 \times P 5 \\
& =0,206 \times 0,235 \\
& =0,048 \\
\mathrm{X}_{2} \rightarrow \mathrm{Z} \rightarrow \mathrm{Y} & =P 2 \times P 5 \\
& =0,417 \times 0,235 \\
& =0,097
\end{aligned}
$$




\section{Pengujian Hipotesis Penelitian}

\section{Tabel 9 Pengujian Hipotesis uji t}

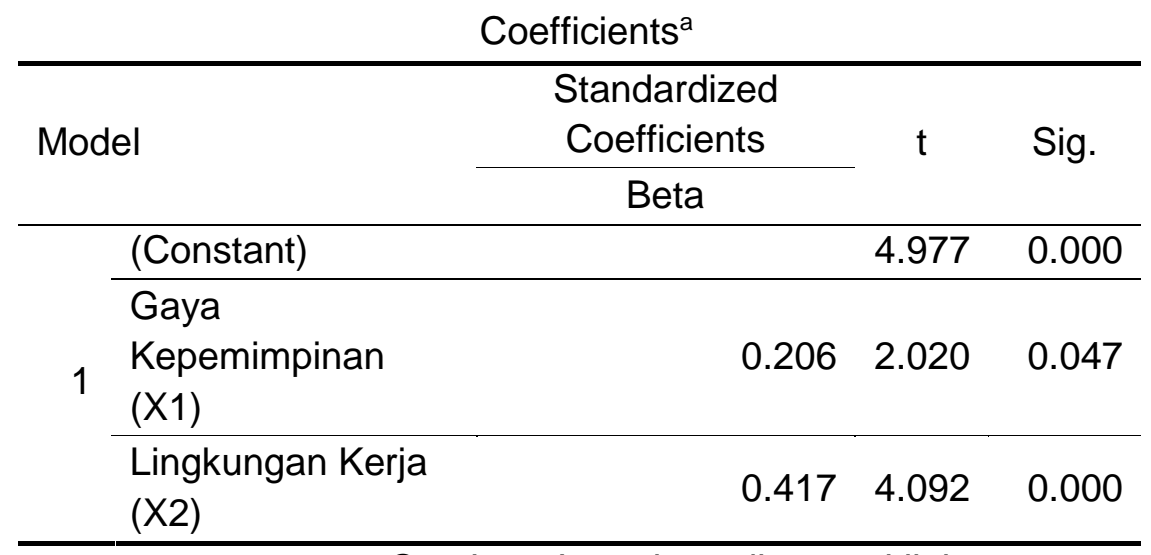

Sumber : Lampiran uji regresi linier

Hipotesis diterima karena $<0,05$ yakni variabel $\left(X_{1}\right)$ punya nilai sig 0.047 Pengujian Hipotesis 2

Berdasarkan tabel 9 didapati nilai t-hitung dari $\left(\mathrm{X}_{2}\right)$ yaitu 4,092 menerangkan nilai signifikan sebesar 0,000 .

Pengujian Hipotesis 3

Tabel 10 Pengujian Hipotesis uji t Coefficients $^{\mathrm{a}}$

\begin{tabular}{|c|c|c|c|c|}
\hline Model & & $\begin{array}{l}\text { Standardized } \\
\text { Coefficients }\end{array}$ & $\mathrm{t}$ & Sig. \\
\hline \multirow{4}{*}{1} & (Constant) & & 3131 & $\cap \cap \cap 1$ \\
\hline & $\begin{array}{l}\text { Gaya } \\
\text { Kepemimpinan (X1) }\end{array}$ & 0.211 & 2.054 & 0.043 \\
\hline & $\begin{array}{l}\text { Lingkungan Kerja } \\
\text { (X2) }\end{array}$ & 0.262 & 2.389 & 0.019 \\
\hline & Motivasi Kerja (Z) & 0.235 & 2.198 & 0.031 \\
\hline
\end{tabular}

sumber : Lampiran uji regresi linier

Berdasarkan tabel 10 t-hitung sebesar 2,054 dan nilai signifikan sebesar 0,043. Jadi Hipotesis diterima.

Pengujian Hipotesis 4

Berdasarkan tabel 4.19 nilai t-hitungnya variabel $\left(X_{2}\right)$ adalah 2,389 dgn nilai signifikan sebesar 0,019 . Yangmana nilai signifikan $0,019<0,05$. Dan Hipotesis diterima. 


\section{Pengujian Hipotesis 5}

Berdasarkan tabel 10 memperoleh nlai t-hitung variable (Z) sebesar 2,198 bersama nilai signifikan sebesar 0,031 . Makadai itunilai sig 0,031 <0,05. Artinya Hiipotesis diterima. Makadari itu (Z) berpengaruh positif dan signifkan terhadap (Y) pada PT. Mina Jaya Lestari Surabaya.

Pengujian Hipotesis 6

Uji hipotesis 6 menggunakan rumus sebagai berikut :

$$
\begin{aligned}
X_{1} \rightarrow Z \rightarrow Y & =P 1 \times P 5 \\
& =0,206 \times 0,235 \\
& =0,048
\end{aligned}
$$

Hasil perhitungan diatas ialah hasik pengaruh secara langsung dari $\left(X_{1}\right)$ terhadap $(Y)$ yaitupada 0,211 , lalu pengaruh tdak langsung bernilai 0,048. Dinyatakan Hipotesis ditolak. Yang artinya $\left(X_{1}\right)$ Melalui $(Z)$ tidak berpengaruh terhadap (Y) pada PT. Mina Jaya Lestari Surabaya.

\section{Pengujian Hipotesis 7}

Pengujian hipotesis 7 menggunakan rumus sebagai berikut :

$$
\begin{aligned}
X_{2} \rightarrow Z \rightarrow Y & =P 2 \times P 5 \\
& =0,417 \times 0,235 \\
& =0,097
\end{aligned}
$$

Menurut hasil perhitungan diatas dapat diketahui nilai pengaruh langsung dari $\left(\mathrm{X}_{2}\right)$ terhadap $(\mathrm{Y})$ menunjukkan nilai 0,262, sedangkan nilai pengaruh tak langsung sebesar 0,097.

\section{Pembahasan Hasil Penelitian}

Pengujian memakai Uji-t. Dihasilkan nilai $\left(X_{1}\right)$ 2,020 dengan nilai signifikan pada 0,047 karena < 0,05. (Hipotesis diterima). Hasil pengujian hipotesis Uji-t. diperolh nilai t-hitung $\left(X_{2}\right)$ 4,092 dgn nilai signifikan sebesar 0,000 . Sehingga nilai sig < 0.05. Hasil uji hipotesis $\left(X_{1}\right)$ sebesar 2,054 dengan nilai signifikannya 0,043. Dijelaskan Uji-t. diperoleh nilai t-hitung var $\left(X_{2}\right)$ 2,389. Dijelaskan nilai t-hitung variabel $(Z)$ sebesar 2,198. Dijelaskan Uji-sobel pengaruh Ingsung $\left(X_{1}\right)$ pada $(Y) 0,211$, lalu nilai pengaruh tdk langsung sebesar 0,048 . Dijelaskan Uji-sobel diketahui nilai $\left(\mathrm{X}_{2}\right)$ ke $(\mathrm{Y})$ 0,262, nilai pengaruh tak langsung sebesar 0,097.

\section{SIMPULAN}

Dijelaskan sesuai pengujian analsis regresi linier berganda dan uji hipotesis, kesimpulannya :

1. Variable $\left(X_{1}\right)$ berpengaruh positiif dan signifikan terhadap variabel $(Z)$

2. Terbukti adanya $\left(X_{2}\right)$ berpengaruh positf serta signifikan terhadap $(Z)$

3. Variable $\left(X_{1}\right)$ brpengaruh positif signifikan terhadap variabel $(Y)$

4. Positif dan signifikan bagi variabel $\left(X_{2}\right)$ terhadap $(Y)$

5. (Z) ada pengaruh positif dan siignifikan terhadap $(Y)$

6. Secara tidak langsung variabel $\left(X_{1}\right)$ tidk berpengaruh terhadap $(Y)$

7. Variable $\left(X_{2}\right)$ secara tidak langsung tidak bepengaruh pada $(Y)$ 


\section{IMPLIKASI}

Berdasar atas kesimpulan dari artikel yang saya teliti diatas, saya menyarankan peniliti selanjutnya membahas variabel independen lain yang lebih luas guna meningkatkan kinerja karyawan serta pengambilan keputusan.

\section{KETERBATASAN PENELITIAN}

Dijelaskan keterbatasan penelitain yakni pada saat melakukan penyebaran kuesioner, terkadang responden tidak memberikan jawaban yang sesuai. Keterbatasan lain yakni peneliti terbatas waktu serta pendanaan

\section{DAFTAR PUSTAKA}

Amirullah. 2015. Pengantar Manajemen. Jakarta: Mitra Wacana Media

Bambang Guritno dan waridin (2005) Guritno,. Pengaruh Persepsi Karyawan Mengenai Perilaku Kepemimpinan, Kepuasan Kerja Dan Motivasi Terhadap Kinerja.JRBI. Vol 1. No 1. Hal: 63-74

Fandy Tjiptono. 2006. "Manajemen Pelayanan Jasa" Yogyakarta: Penerbit Andi.

Nitisemito, Alex. 2011. Manajemen Sumber Daya Manusia. Cetakan Kesembilan.Edisi ke Empat. Jakarta: Ghalia Indonesia.

Sedarmayanti. 2011. Sumber Daya Manusia dan Produktivitas Kerja, CV Mandar Maju, Bandung. 